\title{
Assessment of internal mammary artery and saphenous vein graft patency and flow reserve using transthoracic Doppler echocardiography
}

\author{
F Chirillo, A Bruni, G Balestra, C Cavallini, Z Olivari, J D Thomas, P Stritoni
}

\begin{abstract}
Objective-To investigate transthoracic Doppler echocardiography in the identification of coronary artery bypass graft (CABG) flow for assessing graft patency.

Design-The initial study group comprised 45 consecutive patients with previous CABG undergoing elective cardiac catheterisation for recurrent ischaemia. The Doppler variables best correlated with angiographic graft patency were then tested prospectively in a further 84 patients (test group).

Setting-Three tertiary referral centres.

Interventions-Flow velocities in grafts were recorded at rest and during hyperaemia induced by dipyridamole $(0.56 \mathrm{mg} / \mathrm{kg} / 4 \mathrm{~min})$, under the guidance of transthoracic colour Doppler flow mapping. Findings on transthoracic Doppler were compared with angiography.

Main outcome measures-Feasibility of identifying open grafts by Doppler and diagnostic accuracy for Doppler detection of significant $(\geqslant 70 \%)$ graft stenosis.

Results-In the test group the identification rate for mammary artery grafts was $100 \%$, for saphenous vein grafts to left anterior descending coronary artery $91 \%$, for vein grafts to right coronary artery $96 \%$, and for vein grafts to circumflex artery $90 \%$. Coronary flow reserve (the ratio between peak diastolic velocity under hyperaemia and at baseline) of $<1.9$ (95\% confidence interval 1.83 to 2.08 ) had $100 \%$ sensitivity, $98 \%$ specificity, $87.5 \%$ positive predictive value, and $100 \%$ negative predictive value for mammary artery graft stenosis. Coronary flow reserve of $<1.6$ (95\% CI 1.51 to 1.73 ) had $91 \%$ sensitivity, $87 \%$ specificity, $85.4 \%$ positive predictive value, and $92.3 \%$ negative predictive value for significant vein graft stenosis.

Conclusions-Transthoracic Doppler can provide non-invasive assessment of CABG patency. (Heart 2001;86:424-431)
\end{abstract}

Keywords: blood flow; coronary artery disease; coronary artery bypass graft; echocardiography

Over 400000 patients undergo coronary artery bypass graft (CABG) surgery in the USA each year. ${ }^{1}$ Long term graft patency is the major factor limiting the initial clinical benefits of revascularisation and patient survival. ${ }^{2-4}$ Cardiac catheterisation remains the reference standard for graft patency, but its invasive nature limits its routine use. Results provided by non-invasive techniques such as exercise testing, ${ }^{56}$ thallium scintigraphy, ${ }^{7-9}$ or exercise echo ${ }^{10}{ }^{11}$ are often difficult to interpret in such patients, who may have chest pain unrelated to myocardial ischaemia, ischaemia unrelated to graft obstruction, or a preexisting patchy infarction pattern. Echocardiography has been used previously in an attempt to visualise CABG flow by a transcutaneous approach. ${ }^{12-24}$ Identification of an internal mammary artery to left anterior descending coronary artery anastomosis has been reported by various investigators, with success rates ranging from $61 \%$ to $100 \% .{ }^{12-24}$ However, data on the identification of saphenous vein grafts using transthoracic echo Doppler are lacking. Our aim in this study was to investigate the clinical applicability of transthoracic Doppler echocardiography for identifying flow within the internal mammary artery and saphenous vein conduits, to define the normal and abnormal Doppler velocity flow patterns, and to determine the accuracy of the technique in predicting graft patency.

\section{Methods}

STUDY PATIENTS

The overall protocol was to examine graft patency by catheterisation and transthoracic echo Doppler in an initial cohort of 45 patients (study group), in order to establish criteria for identifying graft flow and the Doppler indices suggesting significant graft stenosis. These criteria were then tested prospectively in a further group of 84 patients (test group).

The initial group of 45 consecutive patients (35 men and 10 women, mean (SD) age 62 (12) years) were scheduled for coronary angiography because of recurrent angina or silent ischaemia occurring at least one year after previous CABG. One patient was excluded because of poor transthoracic Doppler imaging. The mean interval from operation to investigation was 4.9 (1.1) years. Twenty eight patients $(62 \%)$ had a previous myocardial infarction. Most patients had hypertension, diabetes mellitus, or hypercholesterolaemia. Overall, 102 grafts were constructed: 36 left internal mammary artery to left anterior descending coronary artery, three right internal mammary artery to right coronary artery, eight saphenous vein to left anterior descending coronary artery, 33 saphenous vein to right coronary artery, and 22 saphenous vein to circumflex artery branches. The Doppler cut off points indicating stenosis in the internal mammary artery and saphenous vein grafts in this initial 
study group were then tested prospectively in a further cohort of 84 consecutive patients (the test group). The criteria for enrolment were the same as before. All patients in the test group had a sufficient acoustic window.

The hospital's ethics committee approved the study protocol. All patients gave written informed consent to both the invasive and the echocardiographic procedures.

ECHOCARDIOGRAPHY

We used multifrequency transducers allowing on-line switch of frequency separately in cross sectional and colour Doppler, connected to Acuson Sequoia C 256 echocardiographic equipment (Acuson, Mountain View, California, USA). For detection of internal mammary artery grafts we used a 5-7 MHz frequency for cross sectional imaging and $3.5-5.0 \mathrm{MHz}$ for colour Doppler. For detection of saphenous vein grafts we used a $3.5-6.0 \mathrm{MHz}$ cross sectional frequency and a $2.5-3.5 \mathrm{MHz}$ frequency for colour Doppler. Filters and gain setting were properly adjusted to minimise the signal to noise ratio. A colour flow bidirectional map was used; the initial velocity range was set at $\pm 24 \mathrm{~cm} / \mathrm{s}$ for internal mammary artery flow and $\pm 9.6 \mathrm{~cm} / \mathrm{s}$ for saphenous vein graft flow. The Doppler scale limits were subsequently adjusted to optimise the Doppler spectral recording.

To detect internal mammary artery flow, the transducer was placed on the left or right supraclavicular area with the patient in the supine position. The subclavian artery was first imaged in a longitudinal plane at the level of the origin of the vertebral artery. Ninety degree clockwise rotation was made to visualise the origin of the internal mammary artery, a tubular structure (fig 1A) with downward directed flow. Once the position of the internal mammary artery was identified, intraluminal flow signals were obtained using pulsed Doppler (fig $1, \mathrm{~B}$ and $\mathrm{C}$ ). Ultrasound measurements were made using internal software, with appropriate correction for the angle of insonation.

For the detection of saphenous vein grafts, patients were initially examined in the left lateral position from a modified parasternal window. Long axis images of the ascending aorta were first obtained, and the area anterior to the right ventricular outflow tract was carefully examined using combined cross sectional and colour flow mapping. We used a bidirectional colour flow map to distinguish flow signals directed to the anterior aspect of the heart (typically grafts to the right coronary artery) from those directed posteriorly (usually grafts to the circumflex artery). Identification of a bimodal (systolic/diastolic) flow typical of CABG on pulsed wave Doppler allowed us to distinguish between grafts and nonanastomosed thoracic vessels. Inability to demonstrate such bimodal flow by colour Doppler might indicate either an occluded graft or imperfect visualisation; for the purpose of this analysis we considered it to indicate an occluded graft in all cases.

The surgeons at our medical centres generally place right coronary artery bypass grafts anteriorly on the aorta, towards the right side,

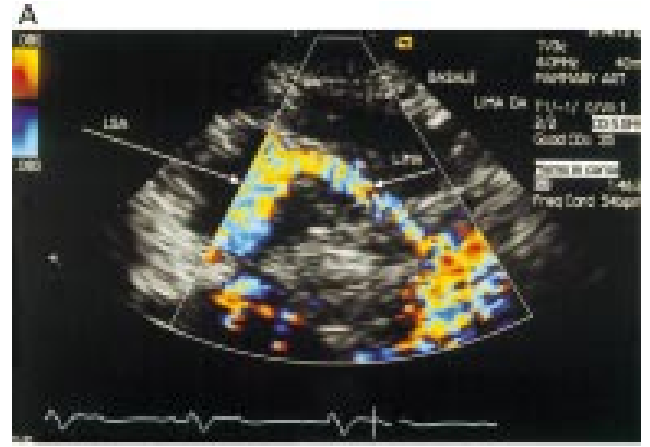

B

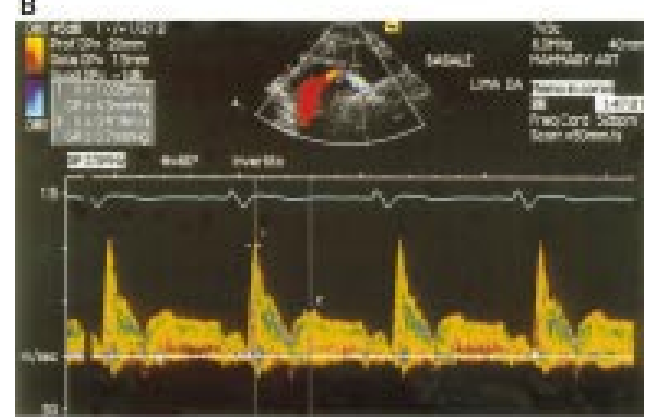

C

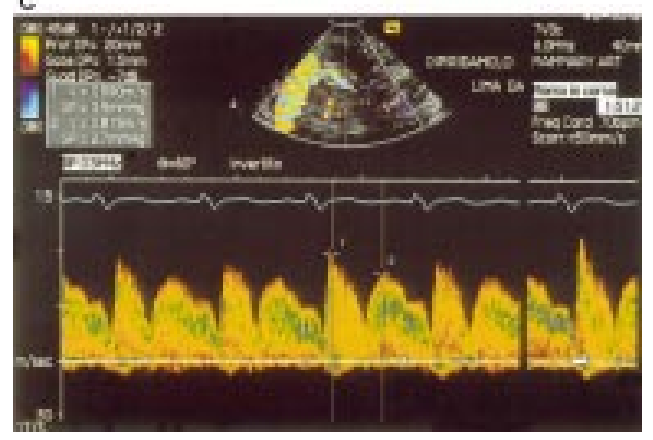

Figure 1 (A) Cross sectional and colour Doppler longitudinal section of the proximal portion of the left internal mammary artery anastomosed to the left anterior descending coronary artery. (B) Doppler interrogation of the proximal portion of a patent graft showed a biphasic flow pattern with a prevalent systolic component and a well represented diastolic flow. (C) After dipyridamole a pronounced increase in diastolic velocity occurred, with a calculated flow reserve of 2.0. LIMA, left internal mammary artery; LSA, left subclavian artery.

approximately $2 \mathrm{~cm}$ above the right coronary ostium; the mid portion of the graft usually lies on the anterior aspect of the right ventricle. Saphenous vein grafts to the left anterior descending coronary artery and its branches are placed on the anterior aorta towards the left, above the level of right coronary artery grafts. Saphenous vein grafts to circumflex branches are placed above and laterally to the left anterior descending coronary artery graft on the aorta. The proximal portion of saphenous vein grafts to the right coronary artery can be visualised by placing the probe initially 1-2 cm lateral to the left sternal border in the second to fourth interspace (to visualise the right ventricular outflow tract) and by then moving the probe $1-3 \mathrm{~cm}$ rightward and tilting it anteriorly. The mid portion of the right coronary graft can usually be visualised with the patient in the right lateral decubitus position, placing the probe $1-2 \mathrm{~cm}$ lateral to the right sternal margin in the fourth to sixth right 


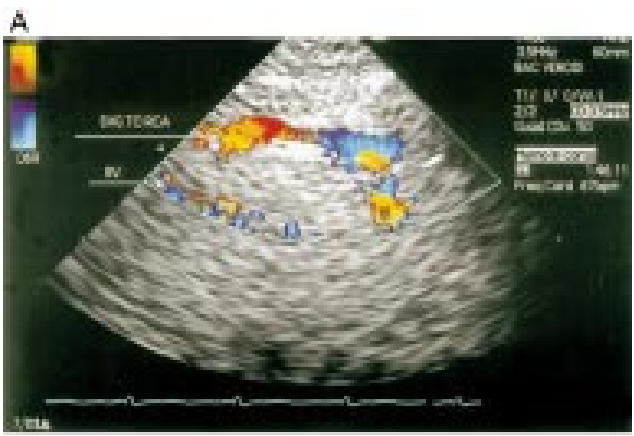

B

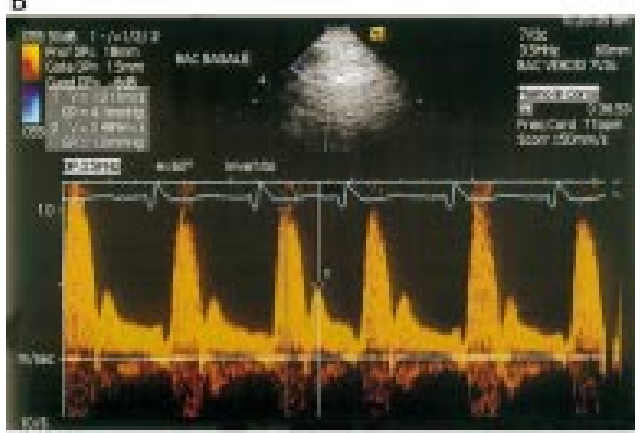

C

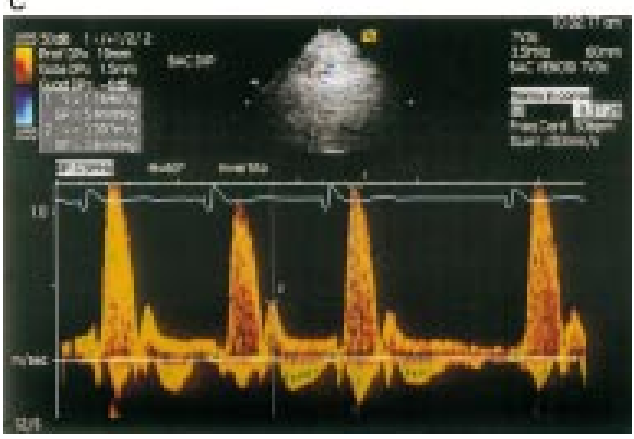

Figure 2 (A) Cross sectional and colour Doppler longitudinal section of the mid-portion of a stenotic saphenous vein graft to the right coronary artery. Note that the graft lies on the epicardial aspect of the right ventricle. (B) Doppler flow velocity spectrum at baseline.

(C) Significant stenosis of the graft was demonstrated because of reduced peak diastolic velocity under dipyridamole. $R V$, right ventricle; SVG TO RCA, saphenous vein graft to right coronary artery.

intercostal space (fig 2). Saphenous vein grafts to the left anterior descending coronary artery are usually imaged with the probe placed 1-3 cm lateral to the left sternal margin in the second to fourth interspace with the patient in left lateral position. The proximal portion of grafts to the circumflex artery is generally placed more lateral to the aorta (that is, more to the left) and it can be imaged by placing the probe in a more leftward and cranial position, whereas the mid and distal portions generally cannot be visualised because of their retrocardiac position.

Diastolic and systolic peak blood velocities and their velocity time-integrals and ratios were measured by tracing out the contour of the Doppler velocity tracing. Values for each parameter were obtained at baseline by averaging measurements from five to seven consecutive cardiac cycles. As a first step we preferred to obtain baseline information from internal mammary artery grafts, and then move to the detection of saphenous vein grafts. Once the baseline Doppler flow velocities had been obtained from all grafts, dipyridamole $(0.56 \mathrm{mg} / \mathrm{kg})$ was given over four minutes and flow velocity in each graft was recorded over the eight minutes following the infusion. During the infusion the transducer was generally kept steady at the site of interrogation of one vein graft, moving subsequently to the other vein grafts; finally internal mammary artery graft flow was assessed. The highest velocities recorded were used in the further analyses. The flow velocity reserve of the graft was calculated as the ratio of the hyperaemic to baseline peak diastolic flow velocity, as in previous studies. ${ }^{20-25}$ All echocardiograms were performed before cardiac catheterisation by an observer blinded to the clinical data. All studies were continuously recorded on S-VHS videotape and significant portions captured in still frames and digitally stored.

Heart rate and blood pressure were monitored throughout the study. After completion of the examination, $120-240 \mathrm{mg}$ theophylline were given intravenously. Patients were monitored in the echocardiology laboratory or on the ward for one hour after the study had been completed. No complications were observed.

Intraoperator and interoperator reproducibility of Doppler diastolic data acquisition was assessed, repeating baseline measurements in 10 internal mammary artery grafts and 10 vein grafts. For this purpose evaluation was performed by the same operator and by two different operators, respectively, on two separate occasions $2-4$ hours apart. Interobserver variability in measurements was determined by having a second independent observer remeasure the stored Doppler velocity recordings in 20 randomly selected patients. We assessed intraobserver variability by having one observer repeat the measurements on spectral curves one month apart in 20 patients.

Table 1 Clinical and cardiac catheterisation data in the study and test groups

\begin{tabular}{lll}
\hline & $\begin{array}{l}\text { Study group } \\
(n=45)\end{array}$ & $\begin{array}{l}\text { Test group } \\
(n=84)\end{array}$ \\
\hline Age (years) & $62(12)$ & $58(7)$ \\
Sex (M/F) & $35 / 10$ & $62 / 22$ \\
Time from surgery (years) & $4.9(1.1)$ & $4.2(0.9)$ \\
IMA graft & 39 & 62 \\
SVG to LAD & 8 & 16 \\
SVG to RCA & 33 & 68 \\
SVG to Cx & 22 & 60 \\
Old MI & 28 & 45 \\
Hypertension & 23 & 45 \\
Diabetes & 10 & 22 \\
Hypercolesterolaemia & 30 & 55 \\
LVEDP (mm Hg) & $12(4)$ & $13(8)$ \\
LVEDVI (ml $\left./ \mathrm{m}^{2}\right)$ & $69(13)$ & $75(16)$ \\
LVESVI (ml $\left./ \mathrm{m}^{2}\right)$ & $34(12)$ & $36(15)$ \\
LVEF $(\%)$ & $53(18)$ & $56(20)$ \\
\hline
\end{tabular}

$\overline{\text { Values are mean (SD). No differences significant between }}$ groups.

$\mathrm{Cx}$, circumflex coronary artery; IMA, internal mammary artery; LAD, left anterior descending coronary artery; LVEDP, left ventricular end diastolic pressure; LVEDVI, left ventricular end diastolic volume index; LVEF, left ventricular ejection fraction; LVESVI, left ventricular end systolic volume index; MI, myocardial infarction; RCA, right coronary artery; SVG, saphenous vein graft. 
Table 2 Contingency tables of patent coronary artery bypass graft at angiography versus detection of coronary bypass flow at transthoracic Doppler echocardiography in the study and in the test population

\begin{tabular}{|c|c|c|c|c|c|c|c|c|}
\hline \multirow[b]{2}{*}{ Echo } & \multicolumn{2}{|c|}{$I M A(n=39)$} & \multicolumn{2}{|c|}{$S V G$ to $L A D(n=8)$} & \multicolumn{2}{|c|}{$S V G$ to $R C A(n=33)$} & \multicolumn{2}{|c|}{$S V G$ to $C x(n=22)$} \\
\hline & Open & Occluded & Open & Occluded & Open & Occluded & Open & Occluded \\
\hline \multicolumn{9}{|l|}{ A. Study population $(n=45)$} \\
\hline Open & 37 & 0 & 6 & 0 & 17 & 3 & 9 & 2 \\
\hline Occluded & 0 & 2 & 1 & 1 & 4 & 9 & 5 & 6 \\
\hline Concordance & $100 \%$ & & $87.5 \%$ & & $79 \%$ & & $68 \%$ & \\
\hline Doppler identification of open grafts & $100 \%$ & & $86 \%$ & & $81 \%$ & & $64 \%$ & \\
\hline \multicolumn{9}{|l|}{ B. Test population $(n=84)$} \\
\hline Open & 59 & 0 & 10 & 0 & 48 & 3 & 35 & 5 \\
\hline Occluded & 0 & 3 & 1 & 5 & 2 & 15 & 4 & 16 \\
\hline Concordance & $100 \%$ & & $94 \%$ & & $93 \%$ & & $85 \%$ & \\
\hline Doppler identification of open grafts & $100 \%$ & & $91 \%$ & & $96 \%$ & & $90 \%$ & \\
\hline
\end{tabular}

$\mathrm{Cx}$, circumflex coronary artery; IMA, internal mammary artery; LAD, left anterior descending coronary artery; RCA, right coronary artery; SVG, saphenous vein graft.

CARDIAC CATHETERISATION

Cardiac catheterisation was performed after the Doppler study on the same day by expert angiographers unaware of the echocardiographic findings. Selective cine coronary angiography was performed from the femoral approach in multiple views by a standard technique. The native coronary circulation and the bypass grafts were selectively opacified. Stenoses were measured using electronic calipers. Results were expressed as per cent lumen stenosis. Graft patency was defined as the absence of significant stenosis ( $\geqslant 70 \%$ ), irrespective of the status of the native circulation proximal or distal to the graft anastomosis. A graft was considered to be occluded if a stump was clearly demonstrated in the aortic root or if the graft was not visualised after aortography.

STATISTICAL ANALYSIS

Continuous data are expressed as mean (SD). Statistical analysis between the study and the test group was performed by analysis of variance for independent samples using the Scheffè $\mathrm{F}$ test. One way analysis of variance (ANOVA) was used to compare the Doppler velocity data in the four groups (patent and stenotic internal mammary artery grafts and

Table 3 Flow velocity characteristics of aortocoronary bypass grafts at baseline and after dipyridamole infusion in the study group

\begin{tabular}{|c|c|c|c|c|}
\hline & \multicolumn{2}{|c|}{ Internal mammary artery graft } & \multicolumn{2}{|c|}{ Saphenous vein graft } \\
\hline & Patent & Stenotic & Patent & Stenotic \\
\hline \multicolumn{5}{|l|}{ A. Baseline } \\
\hline $\mathrm{SPV}(\mathrm{cm} / \mathrm{s})$ & $75(38)^{\star}$ & $78(31)^{\star}$ & $48(18)$ & $45(12)$ \\
\hline DPV $(\mathrm{cm} / \mathrm{s})$ & $41(15)^{\star}$ & $38(15)^{\star}$ & $25(12)$ & $19(6)$ \\
\hline PV ratio & $1.85(0.8)$ & $2.06(0.9)$ & $2.13(1.0)$ & $2.19(0.8)$ \\
\hline SVTI (cm) & $34(18)^{\star}$ & $40(16)^{\star}$ & $18(9)$ & $18(8)$ \\
\hline DVTI (cm) & $28(10)^{\star}$ & $23(8)^{\star}$ & $10(5)$ & $9(4)$ \\
\hline VTI ratio & $1.30(0.6)$ & $1.75(0.5)$ & $1.8(0.4)$ & $2.05(0.7)$ \\
\hline HR (beats/min) & $67(18)$ & $71(13)$ & $65(15)$ & $71(15)$ \\
\hline $\mathrm{SBP}(\mathrm{mm} \mathrm{Hg})$ & $112(29)$ & & $110(27)$ & \\
\hline \multicolumn{5}{|l|}{ B. Dipyridamole } \\
\hline $\mathrm{SPV}(\mathrm{cm} / \mathrm{s})$ & $125(25)^{\star}$ & $101(55)^{\star}$ & $72(18)$ & $68(18)$ \\
\hline $\mathrm{DPV}(\mathrm{cm} / \mathrm{s})$ & $91(18)^{\star} \dagger$ & $40(14)^{\star}$ & $37(13) \dagger$ & $20(6)$ \\
\hline PV ratio & $1.2(0.4)^{\star} \dagger$ & $2.55(1.1)$ & $1.85(0.7) \dagger$ & $3.2(1.2)$ \\
\hline SVTI (cm) & $41(21)^{\star}$ & $48(28)^{\star}$ & $22(8)$ & $21(13)$ \\
\hline DVTI (cm) & $49(10)^{\star} \dagger$ & $28(8)$ & $19(12) \dagger$ & $7(4)$ \\
\hline VTI ratio & $0.8(0.4) \dagger$ & $1.5(0.6)$ & $1.0(0.4) \dagger$ & $2.7(1.4)$ \\
\hline HR (beats/min) & 75 (13) & $80(28)$ & $69(13)$ & $79(28)$ \\
\hline $\mathrm{SBP}(\mathrm{mm} \mathrm{Hg})$ & $145(21)$ & & $138(29)$ & \\
\hline Flow reserve & $2.1(0.3) \dagger$ & $1.0(0.3)$ & $1.9(0.3) \dagger$ & $0.9(0.2)$ \\
\hline
\end{tabular}

${ }^{*} \mathrm{p}<0.05 v$ saphenous vein grafts; $\mathrm{tp}<0.05 v$ stenotic.

DPV, diastolic peak velocity; DVTI, diastolic velocity time integral; HR, heart rate; PV, peak velocity; SBP, systolic blood pressure; SPV, systolic peak velocity; SVTI, systolic velocity time integral; VTI, velocity time integral. patent and saphenous vein grafts before and after dipyridamole). A Fisher protected least significant difference test was performed if the ANOVA showed significant differences. For the initial study group, receiver operating characteristic curves were used to evaluate various level of flow velocity reserve for predicting graft patency. Sensitivity and specificity for graft stenosis and occlusion were calculated in the test group using standard formulas, with the angiographic findings as reference, considering absent detection of flow on echocardiography as occlusion of the graft. A probability value of $\mathrm{p}<0.05$ was considered significant.

\section{Results}

CLINICAL CHARACTERISTICS AND CARDIAC CATHETERISATION DATA

There were no significant differences between the two groups of patients with regard to clinical characteristics and haemodynamic data (table 1).

FEASIBILITY OF DETECTION OF CABG FLOW

These results are shown in table 2. In the study population the feasibility of obtaining Doppler signals from angiographically open grafts was $100 \%(37 / 37)$ for internal mammary artery grafts, $86 \%(6 / 7)$ for vein grafts to the left anterior descending coronary artery, $81 \%(17 / 21)$ for vein grafts to the right coronary artery, and only $64 \%(9 / 14)$ for vein grafts to the circumflex artery branches.

For concordance between Doppler detection of graft flow and angiographic demonstration of patency, we found $100 \%$ agreement for internal mammary artery grafts. The concordance between Doppler and angiography for saphenous vein grafts was rather low because of missed visualisation of some open grafts, and also because of misinterpretation of flow signals from thoracic vessels as flow originating from grafts which were subsequently found to be occluded at angiography. In the test population, agreement between Doppler and angiography increased to $100 \%$ for internal mammary artery grafts, $91 \%$ for saphenous vein grafts to the left anterior descending coronary artery, $96 \%$ for saphenous vein grafts to the right coronary artery, and $90 \%$ for saphenous vein grafts to the circumflex artery. 
Table 4 Diagnostic accuracy of coronary flow velocity reserve as calculated at transthoracic Doppler for prediction of significant graft stenosis in the test population adopting the cut off value of 1.9 for internal mammary artery flow reserve and 1.6 for saphenous vein graft flow reserve

\begin{tabular}{llllll}
\hline & IMA grafts & SVG to LAD & SVG to RCA & SVG to Cx & Global SVG \\
\hline Sensitivity & $100 \%$ & $100 \%$ & $90 \%$ & $89 \%$ & $91 \%$ \\
Specificity & $98 \%$ & $83 \%$ & $89.6 \%$ & $85 \%$ & $87 \%$ \\
Positive predictive value & $87.5 \%$ & $83 \%$ & $86.3 \%$ & $85 \%$ & $85.4 \%$ \\
Negative predictive value & $100 \%$ & $100 \%$ & $92.8 \%$ & $89 \%$ & $92.3 \%$ \\
Accuracy & $98 \%$ & $91 \%$ & $90 \%$ & $87 \%$ & $89 \%$ \\
\hline
\end{tabular}

$\mathrm{Cx}$, circumflex coronary artery; IMA, internal mammary artery; LAD, left anterior descending coronary artery; RCA, right coronary artery; SVG, saphenous vein graft.

BLOOD FLOW PATTERNS IN INTERNAL MAMMARY ARTERY BYPASS GRAFTS

These results are shown in table 3. At baseline none of the Doppler indices considered in patent grafts was significantly different from stenotic grafts, regardless of graft stenosis. After dipyridamole an increase in both systolic and diastolic peak velocities and velocity-time integrals was observed in all grafts, but in non-stenotic grafts the increase in diastolic velocity flow indices was significantly greater and this led to a decrease in the systolic:diastolic ratio. Unfortunately, the large scatter in this variable hindered an accurate prediction of graft patency status. The best correlation with graft stenosis was observed for diastolic flow reserve. The best cut off point in velocity flow reserve was 1.9 (95\% confidence interval (CI) 1.83 to 2.08$)$.

\section{BLOOD FLOW PATTERNS IN SAPHENOUS VEIN GRAFTS}

In saphenous vein grafts the velocity flow profile was similar to that found in internal mammary artery grafts although the velocities recorded were significantly lower (table 3). None of the baseline indices could discriminate between patent and stenotic grafts. After dipyridamole infusion there was a significant increase in diastolic flow velocity in patent grafts, which led to a decrease in systolic:diastolic ratio both for peak velocity and velocity-time integral (table 3). As with internal mammary artery grafts, the scatter in these data was very large, hindering accurate prediction of graft stenosis. The best correlation with graft patency status was observed for a flow reserve with a cut off value of 1.6 (95\% CI 1.51 to 1.73 ).

Table 5 Intraobserver and interobserver variability and reproducibility for Doppler diastolic flow velocity measurements

\begin{tabular}{llll}
\hline & $R(S E E)$ & $\begin{array}{l}\text { Upper limit of agreement } \\
(95 \% \mathrm{CI})\end{array}$ & $\begin{array}{l}\text { Lower limit of agreement } \\
\text { (95\% CI) }\end{array}$ \\
\hline $\begin{array}{l}\text { Intraobserver variability } \\
\text { PDV }\end{array}$ & $0.99(0.9)$ & $2.9(1.3$ to 4.8$) \mathrm{cm} / \mathrm{s}$ & $-3.5(-2.2$ to -4.9$) \mathrm{cm} / \mathrm{s}$ \\
D-VTI & $0.98(1.5)$ & $1.8(0.9$ to 2.8$) \mathrm{cm}$ & $-1.9(-0.8$ to -3.1$) \mathrm{cm}$ \\
$\begin{array}{l}\text { Intraobserver reproducibility } \\
\text { PDV }\end{array}$ & $0.98(2.1)$ & $3.5(1.7$ to 5.9$) \mathrm{cm} / \mathrm{s}$ & $-4.5(-2.1$ to -6.5$) \mathrm{cm} / \mathrm{s}$ \\
D-VTI & $0.97(1.8)$ & $2.1(1.2$ to 5.4$) \mathrm{cm}$ & $-2.3(-1.1$ to -4.8$) \mathrm{cm}$ \\
$\begin{array}{l}\text { Interobserver variability } \\
\text { PDV }\end{array}$ & $0.98(1.8)$ & $3.1(1.5$ to 5.1$) \mathrm{cm} / \mathrm{s}$ & $-4.2(-6.0$ to -2.2$) \mathrm{cm} / \mathrm{s}$ \\
D-VTI & $0.97(1.8)$ & $2.2(0.8$ to 3.3$) \mathrm{cm}$ & $-2.2(-0.7$ to -3.5$) \mathrm{cm}$ \\
Interobserver reproducibility & & & \\
PDV & $0.98(2.1)$ & $6.1(2.2$ to 8.9$) \mathrm{cm} / \mathrm{s}$ & $-5.9(-3.0$ to -8.9$) \mathrm{cm} / \mathrm{s}$ \\
D-VTI & $0.97(1.7)$ & $2.2(1.2$ to 5.7$) \mathrm{cm}$ & $-2.4(-1.1$ to -5.0$) \mathrm{cm}$ \\
\hline
\end{tabular}

CI, confidence intervals; D-VTI, diastolic velocity time integral; PDV, peak diastolic velocity; $R$, coefficient of correlation; SEE, standard error of estimates.
EVALUATION OF GRAFT PATENCY

Results for evaluation of graft patency are shown in table 4 . In the test population angiography disclosed significant stenosis in seven of 59 non-occluded internal mammary artery grafts, five of 11 saphenous vein grafts to left anterior descending coronary artery, 21 of 50 saphenous vein grafts to the right coronary artery, and 19 of 39 vein grafts to circumflex branches. Adopting the cut off values for flow velocity reserve found in the study population, transthoracic Doppler echocardiography showed $100 \%$ sensitivity, 98\% specificity, $87.5 \%$ positive predictive value, $100 \%$ negative predictive value, and $98 \%$ accuracy for the detection of significant internal mammary artery graft stenosis. For saphenous vein grafts the global diagnostic accuracy was lower (89\%), with $91 \%$ sensitivity, $87 \%$ specificity, $85.4 \%$ positive predictive value, and $92.3 \%$ negative predictive value for identification of significant graft stenosis. As for graft distribution, no significant differences were noted.

INTRAOBSERVER AND INTEROBSERVER

VARIABILITY AND REPRODUCIBILITY

As shown in table 5, intraobserver and interobserver variability in diastolic flow velocity variables on repeat measurement was low, whereas reproducibility of these measurements on repeat acquisition was good.

\section{Discussion}

In recent years non-invasive detection of coronary artery bypass graft flow has been carried out by some investigators using the transthoracic Doppler technique. ${ }^{12-24}$ This method, however, has not been widely applied clinically because of many technical problems concerning the detection and recording of bypass flow signals using the transthoracic approach. These are low velocity signals, originating from epicardial structures, moving together with the heart and often hidden by the pericardium and the left pleura. Artefacts and reverberations from the lungs and the thoracic wall represent further technical problems. In published reports, detection of graft flow by transcutaneous Doppler has been achieved for internal mammary artery grafts, ${ }^{12-24}$ right gastroepiploic artery grafts, ${ }^{26}$ and, with more difficulty, saphenous vein grafts to the left anterior descending coronary artery, ${ }^{15}$ but never for vein grafts to the right coronary or circumflex arteries. Chandraratna and colleagues recently reported a high rate of visualisation and measurement of flow velocity and reserve in saphenous vein 
grafts to the right coronary and circumflex arteries using multiplane transoesophageal echocardiography. ${ }^{27}$ However, routine use of transoesophageal echocardiography is limited owing to its a semi-invasive nature.

Recent advances in echocardiographic technology have made possible the transfer of some of the advantages of transoesophageal echocardiography (high frequency probes, high frame rate, separate frequencies for cross sectional and Doppler analysis) to the transthoracic approach. To our knowledge this is the first paper validating a global assessment of CABG flow using a completely non-invasive approach.

\section{ASSESSMENT OF INTERNAL MAMMARY ARTERY} GRAFTS

In our experience internal mammary artery grafts were detectable in all patients, in accordance with the findings of Ehrsam and colleagues, who reported a $100 \%$ detection rate of the ungrafted left and right internal mammary artery using the same echocardiographic system. ${ }^{28}$ Crowley and associates reported that at baseline a systolic to diastolic peak velocity ratio of $>1$ in internal mammary artery anastomosed to left anterior descending coronary artery predicted severe stenosis with a sensitivity of $100 \%$ and a specificity of $85 \%$ on transthoracic Doppler. ${ }^{19}$ In our experience none of the baseline Doppler indices could discriminate between patent and stenotic grafts. This discrepancy may reflect different surgical techniques (our surgeons do not ligate all the branches of the internal mammary artery) and different sites of interrogation of the internal mammary artery. In general we assessed internal mammary artery flow in the proximal portion, where it retains the systolic predominance typical of the vessels of the thoracic wall, whereas more distally the diastolic component becomes prominent. It must be remembered that the internal mammary artery graft diastolic:systolic ratio changes from 0.6 proximally to 1.4 distally $^{29}$; accordingly, the diastolic:systolic ratios must be interpreted in relation to the internal mammary artery interrogation site. We prefer the supraclavicular approach in order to make localisation of the Doppler sample volume at baseline and under hyperaemia as reproducible as possible; using the parasternal approach the probe can be placed either proximally or distally to some of the internal mammary artery collaterals, making the assessment of internal mammary artery flow reserve more difficult. Moreover, in patients with multiple grafts this approach allows a wide spatial separation between the sampling sites of internal mammary artery and saphenous vein grafts, making it easier to distinguish flow signals from different grafts.

Our findings are consistent with some recent studies in which none of the flow indices derived from the baseline Doppler examination allowed a reliable diagnosis to be made in individual subjects because of the large overlap between the stenotic and non-stenotic grafts. ${ }^{20-24}$ This may partly reflect the influence that side branches left unclipped at surgery may have on the blood flow velocity pattern. This problem should be overcome by the use of a vasodilating agent that acts predominantly on the myocardial microvasculature, minimising the confounding effects of internal mammary artery collaterals on the Doppler velocity pattern. The value of flow reserve observed in our study is similar to that found by Pezzano and colleagues ${ }^{20}$ and by Iliceto and associates, ${ }^{30}$ who used dipyridamole, whereas a higher velocity flow reserve (mean 2.4) was found by Katz and colleagues in patent grafts using adenosine.$^{21}$ Low dose dipyridamole is likely to induce submaximal vasodilatation in the coronary microvasculature, leading to flow reserve values lower than those observed for adenosine. ${ }^{31}$ In our experience low dose dipyridamole was preferable because of its longer vasodilating activity and the absence of hyperventilation; this was of great help when evaluating patients with multiple grafts.

ASSESSMENT OF SAPHENOUS VEIN GRAFTS

Saphenous vein grafts are more difficult to identify than internal mammary artery grafts using transthoracic echocardiography, because their location is extremely variable depending on the surgical technique and the individual thoracic conformation. The success rate in achieving satisfactory saphenous vein graft imaging reported in the present study might seem exceedingly high and very difficult to reproduce in everyday practice. Before undertaking this study we practised for a year, comparing echocardiography with images shot in the operating room, with the surgeons indicating the position of each graft before the chest was closed. Knowing the surgical technique is a great help in identifying the course of the vein grafts, which is pivotal to the transthoracic Doppler detection of saphenous vein graft flow. The difference in the detection rate of vein grafts between our study population and the subsequent test group shows the need for a learning period.

The flow profile in saphenous vein grafts was similar to that of internal mammary artery grafts, although all the velocity and flow reserve values were significantly lower. The lower velocities may reflect the larger diameter of the vein conduits, whereas the lower flow reserve may be explained by non-obstructive proliferative changes of the saphenous vein conduits. ${ }^{32}$

Because in most of the patients only small portions of saphenous vein grafts could be visualised, it was very difficult to obtain a longitudinal section of the graft in order to minimise the angle between the interrogating beam and the vessel. This represents a limitation in calculating maximum systolic and diastolic flow velocities and may explain the large scatter in the values obtained. However, because the sample volume location was the same at baseline and after dipyridamole, any Doppler alignment error should be cancelled out when the flow velocity reserve is calculated. 
PREDICTION OF GRAFT PATENCY BY DOPPLER ECHOCARDIOGRAPHY

Flow reserve measurements were essential for assessment of the grafts because the mere presence of blood flow did not signify adequacy of the conduit. The observed negative predictive value of transthoracic Doppler was higher than that of other non-invasive techniques such as thallium tomography, whereas the overall accuracy was not superior to that observed with other methods. $^{7-9}$

There are many possible explanations for the somewhat low specificity observed in our population. Some patent grafts with a low flow reserve supplied myocardium that was partly scarred from previous infarction. Furthermore, many patients had hypertension, diabetes, and hypercholesterolaemia, all of which can impair coronary reserve in the myocardium supplied by a patent graft. ${ }^{33-35}$ In five patients, significant stenosis in the recipient artery distal to the graft anastomosis was evident on angiography, and in four patients the distal runoff of the recipient coronary bed was poor. Under these conditions the vasodilating capacity of the recipient myocardium was probably reduced independent of any graft stenosis. In the light of these factors it is clear that transthoracic Doppler cannot be used on its own for a reliable assessment of graft stenosis. However, it does appear to predict impaired perfusion, whether from graft or native vessel stenosis or myocardial scarring. The excellent negative predictive value is helpful in excluding bypass graft and recipient artery problems, but in the presence of a blunt response the accuracy is not very good.

LIMITATIONS

Our study has several limitations. First, the relatively small study group and possible selection bias may have influenced the calculated sensitivity and specificity values for graft patency. In fact our patients had a high pretest probability of graft occlusion or stenosis. It is conceivable that specificity would have been higher in a lower risk population. However, it must be remembered that in this study predictive values were calculated for each graft and not for each patient. Furthermore, we designed the protocol to select optimal cut off points in the study patients, and then tested these in the second group of patients, showing consistent accuracy.

A second limitation was that the assessment of absolute blood velocity might be limited in some patients by the large incident angle between the Doppler beam and blood flow. However, calculation of the flow reserve allows assessment of flow patterns without the need for absolute values.

Third, the velocity ratio was used as a surrogate of flow reserve: flow within the coronary bypass graft was not calculated because cross sectional visualisation of the graft did not allow an accurate measurement of the diameter of the conduit. The estimated flow reserve would be accurate if the bypass functioned only as a conduit and did not change its diameter during dipyridamole infusion.
Fourth, a functional variable such as the velocity flow reserve was compared with an "anatomical" finding such as graft stenosis, as evaluated at angiography. The limitations of coronary angiography and its poor correlation with functional stenosis severity are well recognised. ${ }^{36}{ }^{37}$ The interpretation of coronary flow reserve is hampered by the variation in normal values determined by the dependency on loading conditions, the influence of collateral blood flow, and the presence of many biological conditions (such as diabetes, hypertension, or haemorheological disorders) which can impair myocardial vasodilatation in the absence of obstructive coronary disease. ${ }^{37-39}$ At present the gold standard technique for evaluating functional severity is the calculation of fractional flow reserve, which requires precise transstenosis pressure measurements. ${ }^{40}$ For our purposes it would have seemed more appropriate to compare the estimated flow reserve by transthoracic Doppler with intracoronary Doppler flow reserve. This technique is not currently performed in our catheterisation laboratory; however, an excellent correlation between the transthoracic and intracoronary flow reserve has recently been reported for internal mammary artery grafts. ${ }^{23}$

Fifth, although treatment was not changed in the interval between the echo and the angiographic studies, one cannot exclude the possibility that there might have been changes in the haemodynamics of some of the patients, with increased heart rate and blood pressure in the catheterisation laboratory. However, it seems unlikely that this would affect the angiographic evaluation of graft status.

Sixth, the Doppler technique used is time consuming, and the high success rate achieved in imaging bypass graft flow by transthoracic Doppler results both from the use of digital ultrasound technology with a dedicated machine and from the expertise of the operators. Therefore, for the technique to be of any clinical value one would need very highly trained echocardiographers.

Finally, the success rate for Doppler identification of graft flow may be highest if the study is performed in the centre where the original surgery was undertaken, because echocardiographers know the position in which the grafts are likely to be found. Consequently this may limit the applicability in other instances where a patient is examined at a different centre or where the precise surgical details are unknown.

\section{CONCLUSIONS}

Careful transthoracic cross sectional, pulsed, and colour Doppler examination can yield a completely non-invasive assessment of flow dynamics of internal mammary artery and saphenous vein grafts. Similar flow patterns are found within vein and internal mammary artery grafts, although vein velocities are generally lower. Absent bypass flow on echo Doppler was strongly predictive of graft occlusion at angiography. A significant increase in Doppler velocity under dipyridamole infusion accurately identified non-stenotic grafts, but a blunted response to dipyridamole could not 
distinguish between stenotic grafts and distal run off problems. Thus, while this echo Doppler technique cannot be considered an alternative to cardiac catheterisation, the finding of normal graft flow and flow reserve may eliminate some unnecessary catheterisations.

Possible clinical applications of the technique may be the evaluation of intermediate stenosis (where calculation of fractional flow reserve is not available at the time of angiography), longitudinal follow up of patients with previous bypass grafts to improve timing of invasive evaluation and possible percutaneous intervention before graft occlusion occurs, identification of culprit lesions in the setting of symptomatic patients with multiple stenosis, and assessment of short term and mid-term results of angioplasty procedures on bypass conduits or on recipient coronary arteries. Moreover, assessment of bypass flow reserve could be combined with the evaluation of segmental wall motion abnormalities induced by dipyridamole, providing simultaneous information on both flow reserve and inducible ischaemia.

Further studies on larger populations are needed to validate the findings of the present study and to assess the clinical value of the technique.

We gratefully acknowledge Stephen G Ellis MD, for his critical revision of the manuscript. Support sources: US National Aeronautics and Space Administration (NCC9-60) (JDT).

1 Vital and Health Statistics. Detailed diagnoses and procedures: National Hospital Discharge Survey, 1991. Series 13: Data from the National Health Survey N.115. Hyattsville, MD: US Department of Health and Human Services, February 1994

2 Bourassa MG, Enjalbert M, Campeau L, et al. Progression of atherosclerosis in coronary arteries and bypass grafts; ten years later. Am 7 Cardiol 1984;53:102-7.

3 Campeau L, Enjalbert M, Lesperance M, et al. Atherosclerosis and late closure of aortocoronary saphenous vein grafts: sequential angiographic studies at two weeks, 1 year, 5 to 7 years and 10 to 12 years after surgery. Circulation 5 to 7 years and 10 to

4 Ellis SG, Brener SJ, DeLuca S, et al. Late myocardial illis SG, Brener SJ, DeLuca S, et al. Late myocardial ischemic events after saphenous vein graft intervention.
Importance of initially "nonsignificant" vein graft lesions. Importance of initially "nonsi

5 Ryan TJ, Weiner DA, McCabe CH, et al. Exercise testing in the coronary artery surgery study randomized population. Circulation 1985;72(suppl V):V31-8.

6 Gohlke H, Gohlke-Barwolf C, Samek L, et al. Serial exercise testing up to six years after coronary bypass surgery: behaviour of exercise parameters in groups with different degrees of revascularization determined by postoperative angiography. Am $\mathcal{F}$ Cardiol 1983;51:1301-6.

7 Ritchie JL, Narahara KA, Trobaugh GB, et al. Thallium201 myocardial imaging before and after coronary revascularization: assessment of regional myocardial blood flow and graft patency. Circulation 1977;56:830-6.

8 Lakkis NM, Mahmarian JJ, Verani MS. Exercise thallium201 single-photon emission computed tomography for 201 single-photon emission computed tomography for
evaluation of coronary artery bypass graft patency. $A m \mathcal{F}$ Cardiol 1995;76:107-11.

9 Khoury AF, Rivera JM, Mahmarian JJ, et al. Adenosine thallium-201 tomography in evaluation of graft patency late after coronary artery bypass graft surgery. $\mathrm{F} \mathrm{Am} \mathrm{Coll}$ Cardiol 1997;29:1290-5.

10 Sawada SG, Judson WE, Ryan T, et al. Upright bicycle exercise echocardiography after coronary artery bypass grafting. Am F Cardiol 1989;64:1123-9.

11 Kafka H, Leach AJ, Fitzgibbon GM. Exercise echocardiography after coronary artery bypass surgery: correlation with coronary angiography. $f$ Am Coll Cardiol 1995;25: 1019-23.

12 Loesse B, Marx R, Sons H. Ultrasonic duplex scanning of the internal mammary artery in coronary artery disease. Circulation 1988;78(suppl II):II-417-19.

13 De Bono DP, Samani NJ, Spyt TJ, et al. Transcutaneous ultrasound measurements of blood flow in internal mammary artery to coronary artery grafts. Lancet 1992; 339:379-81.

14 Van Son JA, Skotnicki SH, Peters MB, et al. Noninvasive hemodynamic assessment of the internal mammary artery in myocardial revascularization. Ann Thorac Surg 1993;55: 404-9.
15 Fusejima K, Takahara Y, Sudo Y, et al. Comparison of coronary hemodynamics in patients with internal mammary artery and saphenous vein coronary artery bypass grafts: a noninvasive approach using combined two-dimensional and Doppler echocardiography. $\mathcal{F}$ Am Coll Cardiol 1990;15: 131-9.

16 Takagi T, Yoshikawa J, Yoshida K, et al. Noninvasive assessment of left internal mammary artery graft patency using duplex Doppler echocardiography from supraclavicular fossa. F Am Coll Cardiol 1993;22:1647-52.

17 Nasu M, Takagi T, Akasaka T, et al. Non-invasive Doppler technique for detection of flow velocity in left interna mammary artery grafts. Cardiovasc Surg 1994;2:207-11.

18 Mauric A, De Bono DP, Samani NJ, et al. Transcutaneous ultrasound assessment of internal thoracic artery to coronary artery grafts in patients with and without ischaemic symptoms. Br Heart $\mathcal{F} 1994 ;$ 72:476-81.

19 Crowley JJ, Shapiro LM. Noninvasive assessment of left internal mammary artery graft patency using transthoracic echocardiography. Circulation 1995;92 (suppl II):II-25-30.

20 Pezzano A, Fusco R, Child M, et al. Assessment of left internal mammary artery grafts using dipyridamole Doppler echocardiography. Am f Cardiol 1997;80:1603-6.

21 Katz WE, Zenati M, Mandarino WA, et al. Assessment of left internal mammary artery graft patency and flow reserve after minimally invasive direct coronary artery bypass. Am f Cardiol 1999;84:795-801.

22 Fukata Y, Horike K, Fujimoto E, et al. Evaluation of the internal thoracic arterial graft patency by the transthoracic Doppler method under continuous intravenous infusion of adenosine triphosphate disodium. Ann Thorac Cardiovasc Surg 1999;5:310-20.

23 Voudris V, Athanassopoulos G, Vassilikos V, et al. Usefulness of flow reserve in the left internal mammary artery to determine graft patency to the left anterior descending coronary artery. Am f Cardiol 1999;83:1157-63.

24 De Simone L, Caso P, Severino S, et al. Noninvasive assessment of left and right internal mammary artery graft patency with high-frequency transthoracic echocardiopatency with high-frequency transthoracic
graphy. f Am Soc Echocardiogr 1999:12:841-9.

25 Gould KL, Kirkeeide RL, Buchi M. Coronary flow reserve as a physiologic measure of stenosis severity. $\mathrm{f} \mathrm{Am}$ Coll Cardiol 1990;15:459-74.

26 Tavilla G, Pijls NH, Berreklouw E, et al. Noninvasive assessment of right gastroepiploic artery graft patency using transcutaneous color Doppler echocardiography. Ann Thorac Surg 1999;67:624-8.

27 Chandraratna PA, Tak T, Ismail Y, et al. Visualization and measurements of flow velocity and flow reserve in aortocoronary saphenous vein bypass grafts by transesophageal echocardiography. Am f Cardiol 1997:80:9558.

28 Ehrsam JE, Spittell PC, Seward JB. Internal mammary artery: $100 \%$ visualization with new ultrasound technology. f Am Soc Echocardiogr 1998;11:10-12.

29 Bach RG, Kern MJ, Donohue TJ, et al. Comparison of phasic blood flow velocity characteristics of arterial and venous coronary artery bypass conduits. Circulation 1993;88:13340

30 Iliceto S, Marangelli V, Memmola C, et al. Transesophageal Doppler echocardiography evaluation of coronary blood flow velocity in baseline condition and during dipyridamole-induced coronary vasodilation. Circulation 1991;83:61-9.

31 Hutchison SJ, Shen A, Soldo S, et al. Transesophageal assessment of coronary flow velocity reserve during "regular" and "high"-dose dipyridamole stress testing. Am f Cardiol 1996;77:1164-8.

32 Campisi R, Czernion J, Karpman HL, et al. Coronary vasodilatory capacity and flow reserve in normal myocardium supplied by bypass grafts late after surgery. $\mathrm{Am} \mathcal{F}$ Cardiol 1997;80:27-31

33 Uren NG, Marraccini P, Gistri R, et al. Altered coronary vasodilator reserve and metabolism in myocardium subtended by normal arteries in patients with coronary artery disease. 7 Am Coll Cardiol 1993;22:650-8.

34 Kern MJ, Bach RG, Mechen C, et al. Variations in normal coronary vasodilatory reserve stratified by artery, gender, heart transplantation, and remote coronary artery disease. f Am Coll Cardiol 1996;28:1154-60.

35 Strauer B. The significance of coronary reserve in clinical heart disease. $f$ Am Coll Cardiol 1990;15:775-83.

36 Topol EJ, Nissen SE. Our preoccupation with coronary luminology: the dissociation between clinical and angiographic findings in ischemic heart disease. Circulation 1995;92:2333-42.

37 Kern JM, De Bruyne B, Pijls NHJ. From research to clinical practice: current role of intracoronary physiologically based decision making in the cardiac catheterization laboratory. $\mathcal{F}$ Am Coll Cardiol 1997;30:613-20.

38 Uren NG, Melin JA, De Bruyne B, et al. Relation between myocardial blood flow and the severity of coronary artery stenosis. N Engl f Med 1994;330:1782-8.

39 Pijls NHJ, Bech GJW, El Gamal MIH, et al. Quantification of recruitable coronary collateral blood flow in conscious man and its potential to predict future ischemic events. $\mathcal{f}$ Am Coll Cardiol 1995;25:1522-8.

40 Pijls NHJ, De Bruyne B, Peels K, et al. Measurements of fractional flow reserve to assess the functional severity of coronary artery stenosis. N Engl f Med 1996;334:1703-8. 